\title{
Research on Buy-Back Contract in Supply Chains Based on Mental Accounting Theory
}

\author{
Xiaole Zhang \\ Jinan University School of Management, Guangzhou, China \\ Email:2897054522@qq.com
}

Received 18 April 2016; accepted 18 June 2016; published 21 June 2016

Copyright (C) 2016 by author and Scientific Research Publishing Inc.

This work is licensed under the Creative Commons Attribution International License (CC BY). http://creativecommons.org/licenses/by/4.0/

c) (i) Open Access

\begin{abstract}
Adopting the concept of mental accounting, the paper analyzes loss-aversion retailer's optimal order quantity under buy-back contract in the two-stage supply chain, and proves the existence and uniqueness of the optimal order quantity. Conclusions show: under the certain degree of loss aversion, there exists a unique repurchase price to achieve supply chain coordination; meanwhile, the system's optimal order quantity decreases with the retailer's loss aversion and increases with the buy-back price.
\end{abstract}

\section{Keywords}

Mental Accounting, Newsboy Model, Loss Aversion, Buyback Contract

\section{Introduction}

By studying people's irrational decision-making behavior in risk scenarios, Kahneman and Tversky put forward the prospect theory. The theory shows that people's psychological reference points influence their feelings about the benefit of the actual decisions, which results in people's irrational decision-making behavior [1]. Schweitzer introduces the loss aversion behavior into classical newsboy model earliest through an experiment in the paper [2]. Since then, scholars pay more attention to the shortage of punishment [3], expected-based point of reference [4], as well as the competitive the newsboy model [5] and etc. to study the loss aversion retailer's optimal order decision.

Mental accounting is the set of cognitive operations used by individuals to organize, evaluate, and keep track of financial activities. This first captures how outcomes are perceived and experienced, and how decisions are made and subsequently evaluated. A second component of mental accounting involves the assignment of activities to special accounts. Expenditures are grouped into categories and spending is sometimes constrained by implicit or explicit budgets [6]. Introducing the concept of mental accounting into classic newsboy model, deci- 
sion-making behavior is independent of reference point, namely, the retailer's decision-making behavior is subject to different accounts in mind. For example, Ho et al. study the multi-regional coordination problem of supply chain system with the assumption that retailers' out stock cost bigger than overbooking and the paper conducts an experiment to verify that the theoretical model can better predict actual retailers' order quantity [7]. Zhang et al. verify that two-stage supply chain channel efficiency decreases with the degree of loss aversion through establishing similar theoretical model [8]. Tong designed three kinds of payment scheme to study the retailer's order decision. Experimental results in the paper cannot be explained by expected utility maximization, time discounts, and loss aversion theory, but "prospective accounting" behavior in the mental accounting theory can explain the experimental data well [9].

Double marginal effect makes decentralized supply chain in a sub-optimal state. But supply chain contracts such as revenue sharing contract and buy-back contract can realize supply chain coordination. For example, Davis et al. study how inventory risk sharing affects the efficiency of channels and distribution of profits by experimental methods, and the value predicted by the model based on mental accounting theory shows that APD contract cannot coordinate the supply chain under bounded rationality environment [10]. Becker-Peth et al. find that buy-back contract based on the mental accounting obviously improves the performance of supply chain under the experimental environment [11].

Unlike the previous literatures, this paper is devoted to coordination of a supply chain consisting of one risk-neutral supplier and one retailer with mental accounting behavior. The major purposes of this paper include: 1) to establish the utility function adopting mental accounting theory, and to find out the optimal strategies of retailer and supplier; 2) to illustrate how variation of parameters influence on optimal decisions of supply chain members.

\section{Assumptions and Models}

Assume that there is a risk neutral supplier and a retailer with mental accounting behavior in a two-stage supply chain system, and retailer face random demand of the market. Demand $x$ is a nonnegative random variable with a probability density function (PDF) $f(x)$ and a cumulative distribution function (CDF) $F(x)$ defined over the continuous interval. Both the supplier and the retailer have the complete knowledge about the demand, profits, costs, risk-aversion preferences and prices. Notations used in this paper are defined as follows (Table 1).

Definite the loss aversion utility function is:

$$
U(x)=-\lambda[x]^{-}+[x]^{+}
$$

where $[x]^{-}$is equal to the absolute value of $x$ if $x$ is negative and 0 otherwise, and $[x]^{+}$is equal to $x$ if $x$ is positive and 0 otherwise. $\lambda$ is Defined as the degree of loss aversion and $\lambda>1$.

This paper adopts the method that Becker-Peth computes mental accounts. Retailer creates a psychological account based on sales revenue, and retailer is loss-averse for loss that is from the leftover product at the end of sales period. Regardless of the shortage cost, under the buy-back contract, utility function for loss aversion retailers is:

$$
U_{\pi_{R}}= \begin{cases}(p-w) x-\lambda(w-g)(q-x) & x \leq q \\ (p-w) q & x>q\end{cases}
$$

The retailer's expected utility function is:

Table 1. The meaning of related symbols in paper.

\begin{tabular}{cccc} 
Notation & Meaning & Notation & Meaning \\
$\boldsymbol{p}$ & Retail price & $R$ & Retailers \\
$\boldsymbol{w}$ & Wholesale Price & Supplier & SC optimal order \\
$\boldsymbol{c}$ & Production cost & $q_{S C}^{*}$ & neutral risk \\
$\boldsymbol{q}$ & Order quantity & $q^{*}$ & Retailer optimal order \\
$\boldsymbol{v}$ & Salvage value & $\left.q^{*}\right)$ & utility function \\
$\boldsymbol{s}$ & Shortage cost & $\pi(*)$ & benefit function \\
$\boldsymbol{g}$ & Buyback price & Expect utility function & \\
\hline
\end{tabular}




$$
E\left[\pi_{R}(x, q)\right]=\int_{\underline{x}}^{q}(p-w) x-\lambda(w-g)(q-x) f(x) \mathrm{d} x+\int_{q}^{\bar{x}}(p-w) q f(x) \mathrm{d} x
$$

We select the model of the buy-back contract with risk neutral members as the benchmark. The retailer's optimal order quantity to maximize the supply chain profit is shown as the Formula:

$$
q_{S C}^{*}=F^{-1}\left(\frac{p-c}{p-v}\right)
$$

\section{Model Analysis}

When investigate the coordination of supply chain under bounded rationality environment, we adopt the criterion that supply chain members maximize their expected return. Thus, we can get the following conclusions.

Theorem 1 Under the supply chain with one loss aversion retailer and one risk neutral supplier, given the buy-back contract $(w, g) \in\{(w, g) \mid 0<g<w, g<w<p\}$, loss aversion retailer have the unique optimal quantity $q^{*}$, and satisfying:

$$
F\left(q^{*}\right)=\frac{p-w}{\lambda(w-g)+(p-w)}
$$

Proof: Taking the first derivative and second derivative respectively for Equation (2) with respect to $q$ :

$$
\begin{aligned}
& \frac{\mathrm{d} E\left[\pi_{R}(x, q)\right]}{\mathrm{d} q}=-\lambda(w-g) F(q)+(p-w) \bar{F}(q) \\
& \frac{\mathrm{d}^{2} E\left[\pi_{R}(x, q)\right]}{\mathrm{d} q^{2}}=-\lambda(w-g) f(q)-(p-w) f(q)<0
\end{aligned}
$$

Therefore, in the domain $\{q \mid q \in(\underline{x}, \bar{x})\}$, loss aversion retailer have the unique optimal order quantity $q^{*}$, and satisfying:

$$
-\lambda(w-g) F\left(q^{*}\right)+(p-w) \bar{F}\left(q^{*}\right)=0
$$

Corollary 1. Given the buy-back contract $(w, g) \in\{(w, g) \mid 0<g<w, g<w<p\}$, Retailers' optimal quantity $q^{*}$ reduce with the increase of $w$, and rise with the increase of $g$.

Proof:

$$
\begin{aligned}
& \frac{\mathrm{d} q^{*}}{\mathrm{~d} w}=\frac{\mathrm{d}^{2} E\left[\pi_{R}(x, q)\right] / \mathrm{d} q \mathrm{~d} w}{-\mathrm{d}^{2} E\left[\pi_{R}(x, q)\right] / \mathrm{d} q^{2}}=\frac{-\lambda F(q)-\bar{F}(q)}{\lambda(w-g) f(q)+(p-w) f(q)}<0 \\
& \frac{\mathrm{d} q^{*}}{\mathrm{~d} g}=\frac{\mathrm{d}^{2} E\left[\pi_{R}(x, q)\right] / \mathrm{d} q \mathrm{~d} g}{-\mathrm{d}^{2} E\left[\pi_{R}(x, q)\right] / \mathrm{d} q^{2}}=\frac{\lambda F(q)}{\lambda(w-g) f(q)+(p-w) f(q)}>0
\end{aligned}
$$

Theorem 1 shows, loss aversion retailer's expected utility function is a concave function, thus ensuring the existence and uniqueness of retailer's optimal order $q^{*}$. Corollary 1 verify that buy-back contract can encourage retailer increase its order quantity

Theorem 2. Given $g \in(0, w)$, there exists the buy-back contract can coordinate the supply chain, and $w$ satisfying:

$$
w=g+\frac{c(p-g)}{\lambda(p-c)+c}
$$

Proof: By the $F\left(q^{*}\right)=\frac{p-w}{\lambda(w-g)+(p-w)}=\frac{p-c}{p}$, we get: $w=g+\frac{c(p-g)}{\lambda(p-c)+c}$.

obviously: $\quad p-w=\frac{\lambda(p-c)(p-g)}{\lambda(p-c)+c}>0, w-g=\frac{c(p-g)}{\lambda(p-c)+c}>0$, thus: $w \in(g, p)$. 
Corollary 2. If buy-back contract $(w, g) \in\{(w, g) \mid 0<g<w, g<w<p\}$ can coordinate the supply chain, Loss-averse retailer received the repurchase price of $g$ increase with the degree of loss aversion $\lambda$, decrease with the suppliers wholesale price $w$; Given other conditions unchanged, the repurchase price of loss aversion retailer of $g$ is greater than the risk neutral retailer's repurchase price $g_{N}$.

Proof: By Equation (6):

$$
g=[p+(\lambda-1) w]-\frac{p(p-w)}{(p-c)}
$$

taking the first derivative for Equation (8) with respect to $\lambda, q$ respectively:

$$
\frac{\mathrm{d} g}{\mathrm{~d} \lambda}=w>0 ; \frac{\mathrm{d} g}{\mathrm{~d} w}=(\lambda-1)+\frac{p}{(p-c)}>0 .
$$

obviously: if $\lambda=1, g=p-\frac{p(p-w)}{(p-c)}<g_{N}$.

Theorem 2 and Corollary 2 show: facing the loss aversion retailers, suppliers can still adopt buy-back contract to achieve supply chain coordination; on the other hand, duing to the behavior of retailer, supplier give greater repurchase price to loss-averse retailer than risk neutral retailer.

Corollary 3. If the buyback contracts can achieve supply chain coordination, given the other parameters constant, retailer's loss aversion behavior forcing supplier reduce wholesale price $w$, which makes the supplier gives lower wholesale price to loss-averse retailers than the risk neutral retailer.

Proof: taking the first derivative for Equation (7):

$$
\frac{\mathrm{d} w}{\mathrm{~d} \lambda}=\frac{-(p-c)}{[\lambda(p-c)+c]^{2}}<0
$$

So $w$ decreases with the $\lambda$, thus: $w<w_{N}$.

Corollary 4. Given the other parameters constant, when the buy-back contract realizes supply chain coordination, the retailer's loss aversion behavior increases the retailer's share of expected return $E\left[\pi_{R}(x, q)\right]$.

Proof: In the coordinated supply chain system, given loss-averse retailer's expect utility function $E\left[\pi_{R_{N}}(x, q)\right]$, supplier's expect revenue $E\left[\pi_{R}(x, q)\right]$, and wholesale price $w$, observed $g>g_{N}$ :

$$
E\left[\pi_{R}\left(x, q^{*}\right)\right]-E\left[\pi_{R_{N}}\left(x, q^{*}\right)\right]=\int_{\underline{x}}^{q^{*}} \lambda\left(g-g_{N}\right)\left(q^{*}-x\right) f(x) \mathrm{d} x>0
$$

Similarly, given buy-back price g, observed $w<w_{N}$ :

$$
\begin{aligned}
& E\left[\pi_{R}\left(x, q^{*}\right)\right]-E\left[\pi_{R_{N}}\left(x, q^{*}\right)\right] \\
& =\int_{\underline{x}}^{q^{*}}\left(w_{N}-w\right) x-\lambda\left(w_{N}-w\right)\left(q^{*}-x\right) f(x) \mathrm{d} x+\int_{q^{*}}^{\bar{x}}\left(w_{N}-w\right) q^{*} f(x) \mathrm{d} x>0
\end{aligned}
$$

\section{Conclusions}

In this study, we consider a supply chain that is consisted of a supplier and a retailer who posses mental accounting behavior in a single period. We analyze the condition under which the supply chain can achieve system perfect solution and provide the corresponding contract terms. Conclusions show: under certain degree of loss aversion, there exists a unique repurchase price to achieve supply chain coordination; meanwhile, the whole system's optimal order quantity decreases with the retailer's loss aversion, and increases with the buy-back price.

There are many related problems that need to be further explored. First, the model we consider is in single period. A good extension to this research may be to consider the model in multiple periods. Secondly, the structure of the supply chain in this paper is simple. It is more appreciate to investigate in a more complicated structure in future research. 


\section{References}

[1] Kahneman, D. and Tversky, A. (1979) Prospect Theory: An Analysis of Decision under Risk. Econometrica: Journal of the Econometric Society, 47, 263-291. http://dx.doi.org/10.2307/1914185

[2] Schweitzer, M.E. and Cachon, G.P. (2000) Decision Bias in the Newsvendor Problem with a Known Demand Distribution: Experimental Evidence. Management Science, 46, 404-420. http://dx.doi.org/10.1287/mnsc.46.3.404.12070

[3] Wang, C.X. and Webster, S. (2009) The Loss-Averse Newsvendor Problem. Omega, 37, 93-105. http://dx.doi.org/10.1016/j.omega.2006.08.003

[4] Herweg, F. (2013) The Expectation-Based Loss-Averse Newsvendor. Economics Letters, 120, 429-432. http://dx.doi.org/10.1016/j.econlet.2013.05.035

[5] Feng, T. and Zhang, Y. (2015) A Behavioral Investigation of the Competitive Newsvendor Problem. SSRN 2676408.

[6] Thaler, R.H. (1999) Mental Accounting Matters. Journal of Behavioral Decision Making, 12, 183. http://dx.doi.org/10.1002/(SICI)1099-0771(199909)12:3<183::AID-BDM318>3.0.CO;2-F

[7] Ho, T., Lim, N. and Cui, T.H. (2010) Reference Dependence in Multilocation Newsvendor Models: A Structural Analysis. Management Science, 56, 1891-1910. http://dx.doi.org/10.1287/mnsc.1100.1225

[8] Zhang, L., Song, S. and Wu, C. (2005) Supply Chain Coordination of Loss-Averse Newsvendor with Contract. Tsinghua Science \& Technology, 10, 133-140. http://dx.doi.org/10.1016/S1007-0214(05)70044-4

[9] Chen, L., Kök, A.G. and Tong, J.D. (2013) The Effect of Payment Schemes on Inventory Decisions: The Role of Mental Accounting. Management Science, 59, 436-451. http://dx.doi.org/10.1287/mnsc.1120.1638

[10] Davis, A.M., Katok, E. and Santamaría, N. (2014) Push, Pull, or Both? A Behavioral Study of How the Allocation of Inventory Risk Affects Channel Efficiency. Management Science, 60, 2666-2683. http://dx.doi.org/10.1287/mnsc.2014.1940

[11] Becker-Peth, M., Katok, E. and Thonemann, U.W. (2013) Designing Buyback Contracts for Irrational but Predictable Newsvendors. Management Science, 59, 1800-1816. http://dx.doi.org/10.1287/mnsc.1120.1662

\section{Submit or recommend next manuscript to SCIRP and we will provide best service for you:}

Accepting pre-submission inquiries through Email, Facebook, Linkedin, Twitter, etc

A wide selection of journals (inclusive of 9 subjects, more than 200 journals)

Providing a 24-hour high-quality service

User-friendly online submission system

Fair and swift peer-review system

Efficient typesetting and proofreading procedure

Display of the result of downloads and visits, as well as the number of cited articles

Maximum dissemination of your research work

Submit your manuscript at: http://papersubmission.scirp.org/ 